\title{
Sol-gel glazes - a safe glass and ceramics coloring approach
}

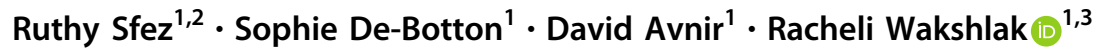

Received: 15 October 2021 / Accepted: 26 November 2021 / Published online: 24 January 2022

(c) The Author(s) 2022

\begin{abstract}
Major attention has been given to safety, environmental, and health hazard issues which arise from using toxic inorganic colorants and pigments in ceramic and glass technologies. A safe alternative is presented, wherein organic colorants approved for human use are entrapped within sol-gel aluminosilicate hybrid matrices and used for glazing porcelain ceramic and glass substrates. Among the colorants used are brilliant blue FCF replacing the toxic cobalt blue, curcumin replacing the toxic cadmium sulfide yellow, and a mixture of carmine and allura-red replacing the toxic cadmium selenide red. Additional advantages of the proposed approach are lowering of energy consumption, offering convenient and efficient recyclability of the colored glasses (thus also solving the current requirements for color-classified recycling), offering a huge library of thousands of organic colorants, opening for the artist and product designer a wide range of visual effects, and opening new artistic coloration methods to be explored. Full characterization was carried out including UV-vis spectroscopy, photoluminescence, topographic thickness analysis, wettability, SEM and XRD analyses, and FIB elemental analyses. The glazes are bright, of the order of 250 microns thick, crack free, chemically stable, with good adherence to both ceramic and glassy surfaces, and recyclable to the pure colorless ceramics or glass by heating. The potential for artistic applications, is demonstrated.
\end{abstract}

\section{Graphical Abstract}

Porcelain tile glazed with an aluminosilicate thick layer, doped with colorants safe for human use.



Racheli Wakshlak

racheliwak@ post.bezalel.ac.il

1 Institute of Chemistry and the Center for Nanoscience and Nanotechnology, The Hebrew University of Jerusalem, Jerusalem 9190401, Israel
2 Department of Materials engineering, Azrieli College of Engineering, Jerusalem 9103501, Israel

3 Department of Ceramics and Glass Design, Bezalel Academy of Arts and Design, Jerusalem 9124001, Israel 


\section{Highlights}

- Metal based glass and ceramics colorants are recognized as major safety, environmental, and health hazard problems.

- A safe alternative is presented, wherein organic colorants approved for human use are entrapped within sol-gel aluminosilicate hybrid matrices.

- These are used for glazing porcelain ceramic and glass substrates, resulting in glazes that are bright, 250 microns thick, crack free, chemically stable, and with good adherence.

- The developed method lowers energy consumption, solves the recyclability problem, and offers a huge library of colorants, opening for the artist and product designer a wide range of opportunities.

\section{Introduction}

A bench-mark Round Table Report was presented at the 2018 Glass Art Society (GAS) Conference in Murano, Italy, the historic artistic glass making site, entitled "The Future of Glass Color" [1]. The report opens with the following statement: "Artistic glass production in Murano island is currently facing a threatening situation, which involves several aspects ranging from environmental and socioeconomic to scientific issues. The goal of the round table is to properly and fully address the nature of the problems related to glass color and of the present situation due to the prohibition of the use of some toxic compounds." The Report lists these toxic compounds - including compounds of cadmium, lead, nickel, arsenic, antimony-and stresses the following appeal (originally in bold-red letters):'Is there any solution to comply with health and environmental issues without killing Murano local artistic industry?"

In fact, that troublesome situation exists not only for artistic and decorative applications of glass but is a general problem of the colored glass industry in general, from the points of view of atmospheric fall-out of metals around glass manufacturing areas [2] polluting air and soil [3]; from the point of view of glass dumps direct pollution of soils and water resources [4]; from the point of view of the alarming reports of increased cancer incidence around glasswork sites [5]; and more [6]. The problem extends also to the variety of human uses of colored glasses and ceramics, such as enameled decorations of bottled beverages [7], a report which also calls for safer decorative alternatives. These problems affect and are relevant to the artist, the technician and factory worker, and the general public neighboring glass and ceramic activity. It is therefore not surprising that in the past few years, EU and US-EPA regulation authorities have defined testing methodologies for the migration of heavy metal colorants from ceramic and glass articles, specifying maximum leaching levels for toxic metals, such as cadmium and lead [8]. Restriction levels for other metals such as cobalt, chromium, nickel and more [8] are now being considered as well.

In this report, we provide a route for addressing the appeal of the Murano 2018 Report and its more general aspects as outlined above. The solution we offer here relates, as a first step, to colored glazing of ceramic and glassy substrates. Specifically, it addresses the fact that the use of the classical colorants was dictated by the very high temperatures of firing needed for glass and ceramic processing, thus limiting the colorants to such that can withstand the high temperatures. Organic and bio-organic dyes, on the other hand, provide an extremely rich pallet of colors, shades, and hues which are safe for human use. Our solution is based on these dyes. As early as 1985 we showed [9] that glassy thin films of silica and silica-titania can be colored with organic dyes, by the use of the lowtemperature sol-gel process. This early demonstration evolved over the years to a useful tool in materials for optics and found plenty of applications, which are described in numerous publications [10-12]. The world of glass and ceramics has been slow in adapting that technology, and one of the prime aims of this report is to draw here again the attention to this approach to glassy materials. The temperature-friendly sol-gel technology offers a potential wide-scope solution for that need, by enabling the introduction of safe, environmentally friendly organic colorants into a hybrid glassy network, which otherwise would be completely burned out if they were used in the traditional ceramic and glass making. In fact, the sol-gel process holds many other benefits in the context of this report:

- Lowering of energy consumption by dramatically lowering the coloring processing temperatures.

- Enabling the artist to coat finished pieces without concern about the integrity of the artwork, which otherwise would have to go through a high temperature glaze firing.

- Offering convenient and efficient recyclability of colored glasses into a reusable colorless glass by heating to organics-decomposition temperatures. This also solves the current requirements for color-classified recycling.

- Offering a huge library of thousands of organic colorants, opening for the artist and product designer a wide range of visual effects. This pallet of colors is by far richer than the current library of hightemperature resistant colorants and pigments, including the safe ones. 
- Opening new artistic methods to be explored-studio artists such as potters and glass artist are constantly seeking new ways of artistic expression. The sol-gel approach provides an entire platform of new possibilities to combine organic and inorganic materials in the design and decorations of ceramic and glass artworks.

Here we demonstrate these features with a sol-gel formulation for color-glazing of ceramic surfaces with an aluminosilicate hybrid glassy coating. Whereas the coating of glass surfaces with organically colored sol-gel doped films is well-known [13, 14], the coating of ceramic bodies with such colored glazes is, to the best of our knowledge, unknown. Furthermore, in general, plain (uncolored) sol-gel coatings on porous ceramics are by far less explored than on glass--some representative examples are [15-17]. Ceramics are therefore at the focus of this report, using fired porcelain discs prepared from a commercial plastic clay. For comparative purposes, further characterization and proof of concept, we also used the same glaze procedures for coating glass substrates. The glaze is doped with safe organic colorants, permitted for food, drug and cosmetic ( $\mathrm{E}$ and FD\&C listings) applications (Scheme 1). The leading color we used for this study is brilliant blue FCF (E133, FD\&C Blue 1), a blue colorant used in processed foods, medications, dietary supplements, and cosmetics, with the aim of replacing the toxic cobalt blue. Additional dyes used in this study were curcumin (E100), a natural yellow colorant aimed at replacing the toxic cadmium sulfide yellow, and a mixture of the natural colorant carmine (E120) and of allura-red (E129, FD\&C red 40) colorant aiming at replacing the toxic cadmium selenide red. The need to find such replacements was stressed in the Murano report [1]. In addition, combinations of brilliant blue with the yellow tartrazine (E102, FD\&C Yellow 5) were used to demonstrate the ability for creating other desired colors and shades, green in this case. Being fluorescent, curcumin also demonstrates the optical effects options opened by the use of safe organic colorants.

We show that these coatings are thick (of the order of a few hundred microns), crack free, chemically stable in air, stable to solvents such as acetone, ethanol, isopropanol, and soapy water, with good adherence to both ceramic and glassy surfaces, and completely recyclable by firing to $950{ }^{\circ} \mathrm{C}$. Full characterization of the films is provided, including UV-vis and fluorescence spectroscopies, profilometry thickness and roughness measurements, optical and SEM microscopies, EDS elemental analyses, XRD analyses, FIB tomography, contact angle measurements water wetting, and scratch resistance. We conclude the report with a brief demonstration of the artistic horizons which were opened.

\section{Experimental details}

\subsection{Safety note}

All of the procedures and chemicals handlings should be carried out while wearing safety goggles and gloves, and performed in a well-ventilated area, preferably in a fume hood or by wearing an air-purifying respirator. Store the silicate and aluminate precursors in closed vessels, refrigerated.

\subsubsection{Chemicals and materials}

Aluminum tri-sec-butylate (ASB, Alfa Aesar), 3glycidyloxy-propyltrimethoxysilane (GPTMS, ChemImpex Int'l), phosphoric acid 85\% (Fluka), dimethylsulfoxide (DMSO, Bio-Lab), acetylacetone (Alfa Aesar) and isopropanol (Acros) were used as received. WBH kaolin powder with median particle size of $2 \mu \mathrm{m}$ was purchased from Sibelco Deutschland $\mathrm{GmbH}$ with the following chemical composition according to the manufacturer $(\%$ weight): $\mathrm{SiO}_{2}$ 57.7, $\mathrm{TiO}_{2} 0.2, \mathrm{Al}_{2} \mathrm{O}_{3} 37.5, \mathrm{Fe}_{2} \mathrm{O}_{3} 0.90, \mathrm{CaO}$ 0.10, $\mathrm{MgO} 0.40, \mathrm{~K}_{2} \mathrm{O} 3.10, \mathrm{Na}_{2} \mathrm{O}$ 0.10. Curcumin, allura red, carmine, brilliant blue FCF and tartrazine were from Sigma-Aldrich. Porcelain 'Audrey Blackman' pottery clay body was purchased from Goerg \& Schneider with the following chemical composition by $\%$ weight according to the manufacturer: $\mathrm{SiO}_{2} 69.8, \mathrm{Al}_{2} \mathrm{O}_{3} 25.0, \mathrm{TiO}_{2} 0.1, \mathrm{Fe}_{2} \mathrm{O}_{3}$ 0.4, $\mathrm{CaO} 0.5, \mathrm{MgO} 0.4, \mathrm{~K}_{2} \mathrm{O} 2.9, \mathrm{Na}_{2} \mathrm{O}$ 1.0.

\subsection{The coated substrates}

$2.5 \mathrm{~cm}$ in diameter and $3 \mathrm{~mm}$ thick porcelain disc were prepared by rolling out a lump of the plastic porcelain clay to a flat sheet with a slab roller and cutting the resulting slab with a cookie cutter. Then, the cut discs were evenly dried for a week in the open air by placing them between two wooden boards. The dried discs were fired to $1220^{\circ} \mathrm{C}$ in a ceramic kiln. According to the manufacturer, such firing of this clay leads to a porous material with $0.1 \%$ water absorption. Standard soda-lime silicate microscope slides $(25.4 \times 76.2 \mathrm{~mm}$, Marienfeld) were used for supportive and comparative purposes. All substrates were rinsed thoroughly in distilled water and dried in an oven before use. The clean substrates were kept in a closed vessel.

\subsubsection{Preparation of the dye solutions}

Dye solutions were prepared by dissolving $10 \mathrm{mg}$ of dye (or dyes mixtures) in $0.5 \mathrm{ml}$ DMSO. Lower concentrations, down to $1 \mathrm{mg}$ of dye in $0.5 \mathrm{ml}$ of DMSO, were used to obtain various shades. For the preparation of the red colored coating, equal weights of allura red and carmine were taken. 
<smiles>CCN(Cc1cccc(S(=O)(=O)[O-])c1)c1ccc(C(=C2C=CC(=[N+](CC)Cc3cccc(S(=O)(=O)[O-])c3)C=C2)c2ccccc2[S+](=O)[O-])cc1</smiles>

Brilliant Blue FCF

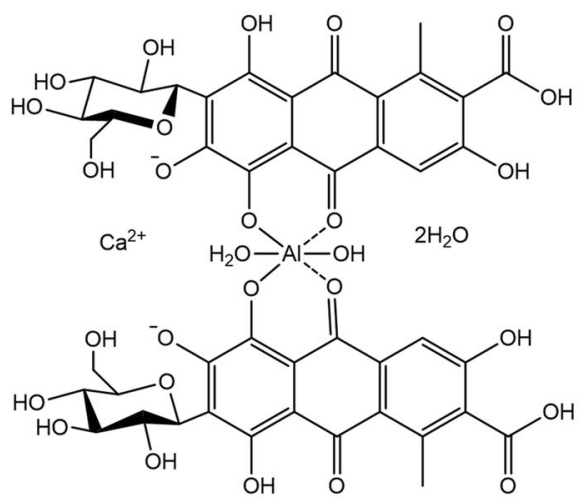

Carmine

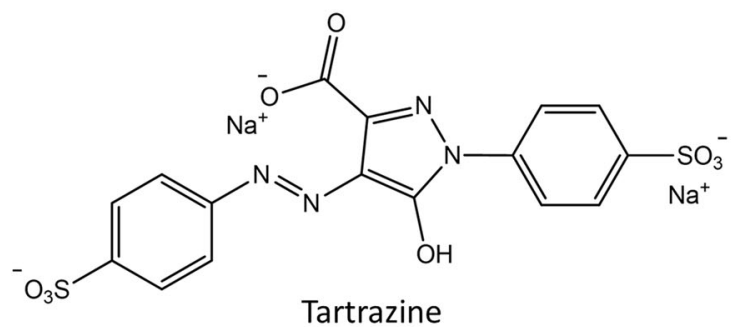

Tartrazine<smiles>Cc1cc2nc3cc(C)c(N)cc3[n+](-c3ccccc3)c2cc1N</smiles>

Safranin

Scheme 1 Organic colorants used in this study

\subsubsection{Preparation of the coating solution}

The sol preparation procedure is a modification of ref. [18]: $1.3 \mathrm{~g}(5.27 \mathrm{mmol}, 1.34 \mathrm{~mL})$ of aluminum tri-sec-butylate (ASB) and $1.8 \mathrm{~mL}$ of isopropanol were mixed and stirred in<smiles>COc1cc(/C=C/C(=O)CC(=O)/C=C/c2ccc(O)c(OC)c2)ccc1O</smiles>

\section{Curcumin}<smiles></smiles>

Allura red<smiles>CCN=c1cc2oc3cc(NCC)c(C)cc3c(-c3ccccc3C(=O)OCC)c-2cc1C</smiles>

Rhodamine 6G<smiles>O=C(O)c1ccccc1-c1c2ccc(=O)cc-2oc2cc(O)ccc12</smiles>

Fluorescein a closed vessel until a clear homogenous solution was formed. Then $0.50 \mathrm{~g}(5.0 \mathrm{mmol}, 0.51 \mathrm{~mL})$ acetylacetone was added and the solution stirred for additional $5 \mathrm{~min}$. The combined mixture was added to $5.0 \mathrm{~g}(20 \mathrm{mmol}, 5.11 \mathrm{~mL})$ of 3-glycidyloxypropyltrimethoxysilan (GPTMS) pre-cooled 
by ice, to which $1.4 \mathrm{~g}$ ( $77 \mathrm{mmol}, 1.4 \mathrm{~mL})$ of triple distilled water (TDW), $260 \mu \mathrm{L}$ of $0.1 \mathrm{M}$ phosphoric acid and $8 \mathrm{mg}$ of Kaolin mineral powder were also added in that order. The combined suspension was stirred for 2 hours in a closed vessel until it became clear. This stock solution can be kept refrigerated in a sealed flask for several weeks.

\subsubsection{Coating procedures}

$1.0 \mathrm{~mL}$ of the sol solution was transferred to a screwed capped vial and mixed with $50 \mu \mathrm{L}$ solution of the chosen dye solution. The sol/dye mixture was then evaporated at $40{ }^{\circ} \mathrm{C}$ under reduced pressure to $1 / 3$ of the original volume, resulting in a viscous liquid. The viscous liquid was applied by brushing on the clean porcelain or glass substrates, followed by tilting movements to assure homogeneous coating. The coated substrates were dried at room temperature overnight and then at $80^{\circ} \mathrm{C}$ for another 24 hours. When removed from the oven, it is important to keep the warm coated substrates wrapped to allow the samples to slowly cool to room temperature in order to prevent the cracks formation. For transparent colorless coating, $50 \mu \mathrm{L}$ of DMSO with no dye were added to the sol solution before volume reduction. Double coating was also carried out by repeating the mixture brushing step on top of an already coated disk followed by a second drying round.

\subsubsection{Artistic work}

Premade porcelain objects (beads, flat substrates, etc.) were brushed-on with a "freestyle" manner. For the preparation of the beads, the coating stage was carried out in a "two sides" steps: one side was coated first, then allowed to dry at room temperature, then baked at 80 degrees for 12 hours, and then the other side of the bead was coated and processed in the same way.

\subsubsection{Instrumentation}

SEM images coupled with EDS detector were obtained with FEI MAGELLAN 400 L XHR SEM. All samples were sputter-coated with Iridium metal prior to the SEM imaging. Optical microscopy was performed with an Olympus BX6000 microscope (Tokyo, Japan). Average surface roughness was determined with Optical Profilometer Countour GT-K1, Bruker. FIB tomography was acquired with Helios Nanolab 460F1Lite Dual Beam Focused Ion Beam/Scanning Electron Microscope (ThermoFisher, former FEI). XRD analyses of the coated porcelain substrates were carried out with a Rigaku SmartLab powder diffractometer using $\mathrm{Cu}-\mathrm{K} \alpha$ radiation $(\lambda=1.54 \AA)$ at a scanning rate of $3 \mathrm{deg} / \mathrm{minute}$. UV-vis spectra were acquired with a Shimadzu spectrophotometer UV-3101PC on glass substrates, or dyes solutions in $\mathrm{H}_{2} \mathrm{O}$ :DMSO mixtures. Fluorescence spectroscopy was conducted with Edinburgh Instruments FLS920 fluorometer. Contact angle measurements were performed with OCA 15EC DataPhysics.

\section{Results and discussion}

The recommended procedure described in the Experimental Details section forms an aluminosilicate network by the co-polymerization of the aluminum oxide precursor, ASB, with the silicate precursor, GPTMS, which is decorated with epoxy handles (the glycidyloxy groups) for better adhesion, and with kaolin particles, an inorganic thickening and thixotropic agent, the role of which is to improve the leveling of the coating and eliminate surface defects from the application process itself. The developed procedure is the result of a lengthy process of optimization and screening of various potential components, all aimed at solving problems such as fractured coatings, uneven coating, formation of brush strokes, poor adherence, or opaqueness. We also had in mind simplifications aimed to make the procedure non-chemist friendly. Very briefly, on the way to the successful aluminosilicate procedure, some of the other tested options were various silanes (tetramethoxysilane, tetraethoxysilane and some trialkoxysilane analogs with various substituents such as methlytrialkoxysilane), various other fillers (such as fiberglass and silica beads), and a variety of different surfactants (such as sodium bis(2-ethylhexyl) sulfosuccinate, cetrimonium bromide, sodium dodecyl sulfate) and polymeric surfactants (polydiallyldimethylammonium chloride, polybrene, and SOLSPERSE 41000). Eventually, it was found that surfactants are not needed at all.

Figure 1 shows pictures of the colored sol-gel glazes (denoted dye@SG) and of the colorless glazes on



Fig. 1 Colored sol-gel glazes coated on porcelain disc and on glass slides: (a) colorless coating. (b) Curcumin@SG. (c) Cramine+allura red@SG. (d) Brilliant blue FCF@SG 
Fig. 2 Optical microscope porcelain disc: (a) before and (b) after glazing with Brilliant blue FCF@SG. Insert: one crystallite enlarged. Real colors are shown reflection mode views of a
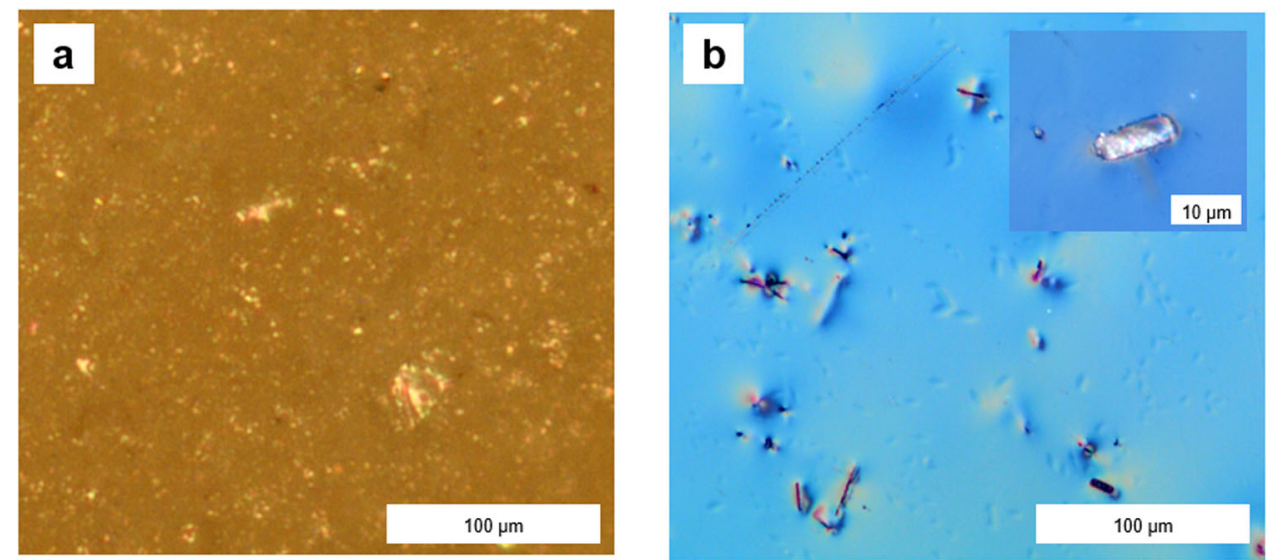

Fig. 3 SEM images of a porcelain disc: (a) before and (b) after coating with Brilliant blue FCF@SG. Insert: one crystallite enlarged (c) Cross-section of (a). (d) Cross-section of doubly glazed porcelain disc. The interfaces are indicated with white arrows; the thicknesses are indicated as well
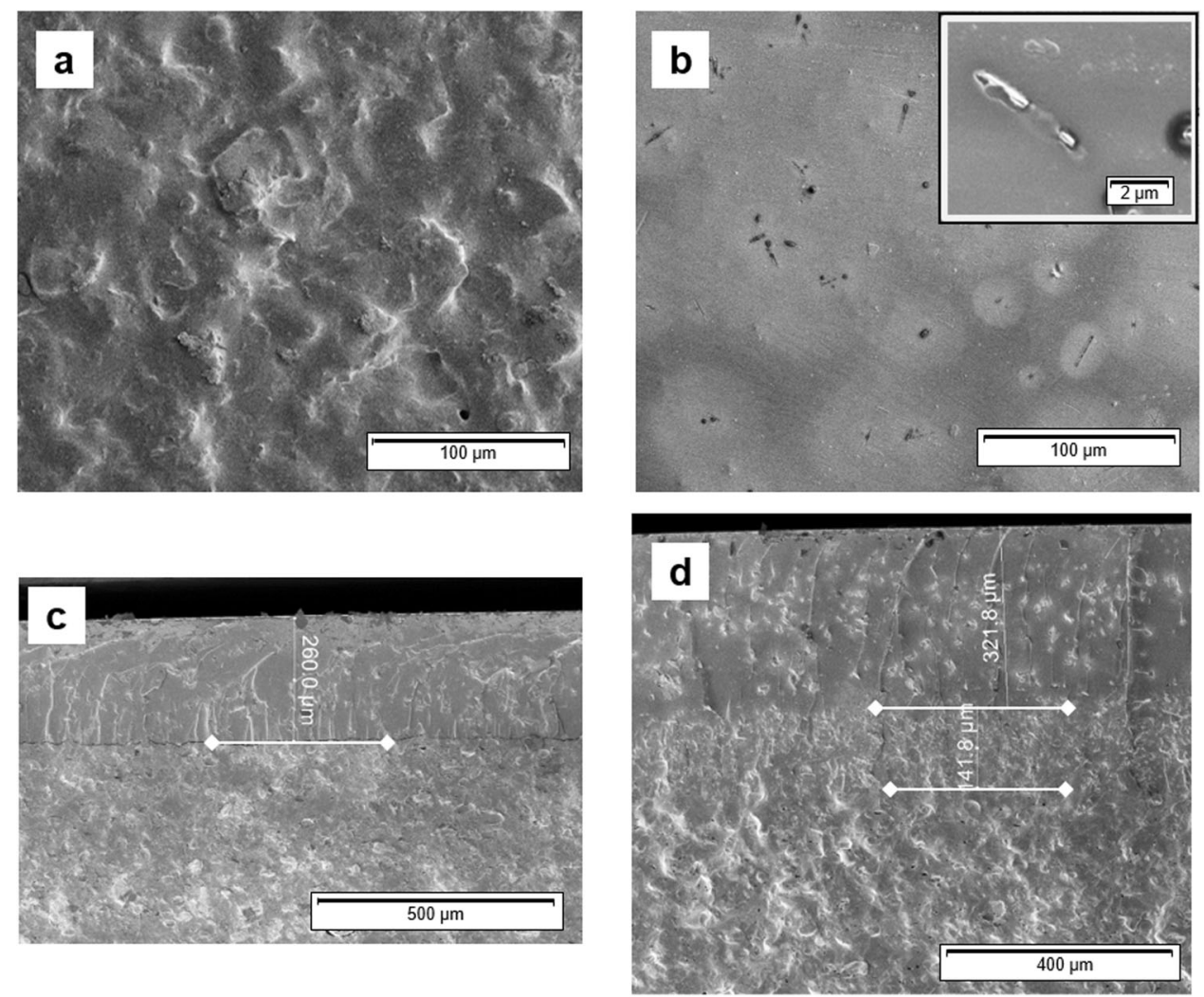

porcelain discs and, for comparison, on standard glass slides. All coatings are highly glossy and fully preserve the characteristic color of the dye molecules or of the combination of the dye molecules used. Having no apparent difference in the coatings quality for both surfaces, which are different in character and in composition, namely the porcelain being porous and rough compared to the smooth surface of the glass slide, points to the high adherence of the coating formulation to hydroxylated surfaces in general, involving both strong hydrogen bonds and covalent bonds. Furthermore, the porosity of the ceramic substrate may also contribute to the anchoring of the dye and the coating itself.
Typical optical microscopic views and HR-SEM images of the porcelain substrates discs before and after being coated with a dye@SG glaze are shown in Figs. 2 and 3. It is seen that applying the brilliant blue FCF@ SG glaze to the porcelain disc changes the surface morphology from rough and uneven (Figs. 2a and 3a) to smooth (Figs. 2b and 3b; brushstrokes can be noticed, seen only under SEM). It is also seen that the coating contains tiny crystals (see inserts in Figs. $2 b$ and $3 b$ ) which are attributed to a common form of alumina derived from the sol-gel process (see XRD analysis discussed below). Cross-section view (Fig. 3c) obtained by cutting the disc shows a near-perfect coating with a typical texture repeating itself quite homogeneously, 

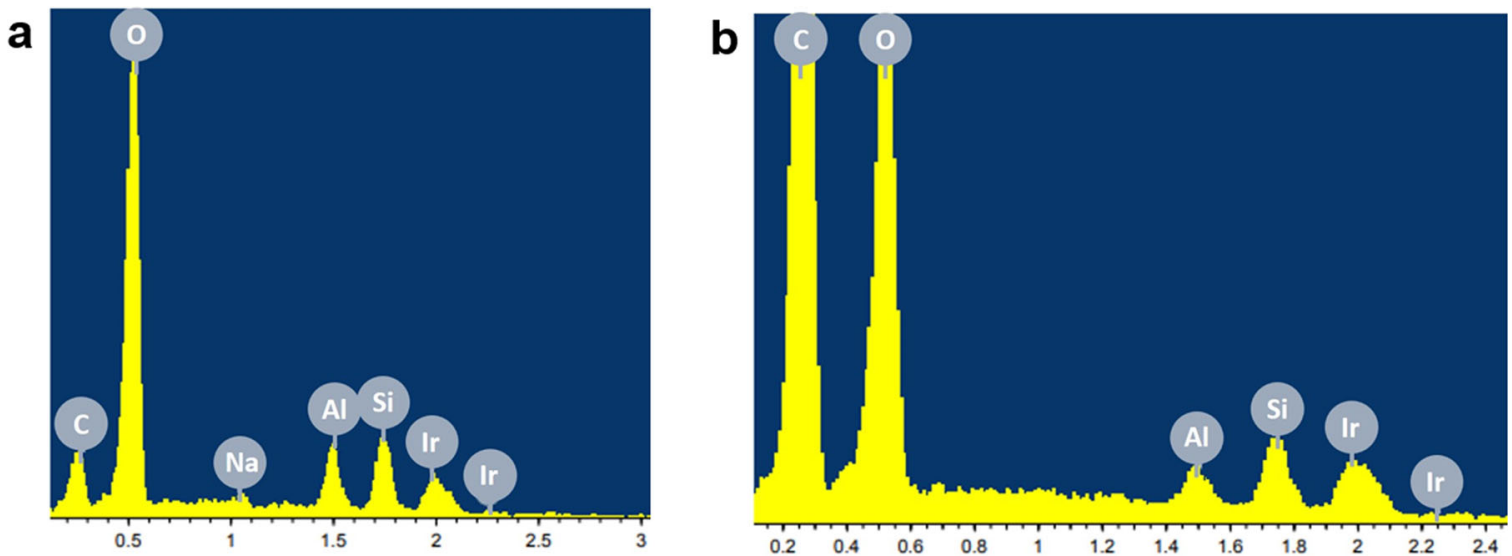

Fig. 4 EDS of a porcelain disc: (a) before and (b) after coating with Brilliant blue FCF@SG

reflecting sub-micron heterogeneity of phases, including some alumina crystallinity. The top surface is smooth, giving it the glossy appearance. The thickness of $\sim 260 \mu \mathrm{m}$ (Fig. 3c) is of the order of the magnitude of standard thicknesses of ceramic glazes $(75-500 \mu \mathrm{m}$ [19]). The interface is also seen, slightly separated because of the cutting process. However, a double coating process strengthens the mechanical stability, and the layers are tightly held even after cutting (Fig. 3d). Micro-elemental analysis by EDS on the SEM images, Fig. 4 (a - before, b - after coating), confirms the aluminosilicate similarity between the substrate and the coating, and also shows the carbon of the glycocidoxy organic chains.

Yet another method was used for thickness and chemical composition determinations, that is, combining focus ion beam (FIB) milling in a SEM instrument coupled with micro-elemental analysis EDS. In this method, a porcelain disc coated with the glaze was cross-sectioned by cutting and milled to a depth of 300 micron by high energy gallium ions striking the surface, and then the formed carter was analyzed by EDS. Figure 5 shows the profiling of a cross-sectioned porcelain disc glazed with brilliant blue FCF@SG: the depth profile of aluminum (Fig. 5b) represents the aluminosilicate porcelain surface, and that of carbon (Fig. 5c) represents the organic constituent of the coating. Going from the deepest end of the crater to the top surface of the coating, it is seen that there is a steep decay in the aluminum counts at about 60 microns, a point that can be referred to the porcelain surface, the remaining 240 microns of the path is attributed to the coating thickness. The carbon profile provides the complementary picture to the above observation: starting from a zero count at the depth of the crater, the carbon count begins to increase at $\sim 60$ micron. Note that the $\mathrm{Al}$ profile changes more gradually than the $\mathrm{C}$ profile, and this is due to the fact that both the glaze and the porcelain are $\mathrm{Al}$ materials. The intensity fluctuations in both the $\mathrm{Al}$ and the $\mathrm{C}$ profiles are indicative of the local inhomogeneity of the various coating's components, that is, the organic aluminosilicate hybrid sol-gel network, the alumina crystallites, and the organic molecules.

Typical XRD analysis of the sol-gel coated porcelain and of the uncoated porcelain disc are seen in Fig. 6. The amorphousness of the coating phases is clearly evident by the presence of a broad peak, typical of the amorphous silica phase [20], on top of which diffraction pattern lines of crystalline phases are apparent. Noticeably, these crystalline diffraction patterns lines match those of crystalline alumina gel (at $2 \theta=11^{\circ}, 23^{\circ}, 24^{\circ}, 25^{\circ}, 26^{\circ}, 27^{\circ}, 33^{\circ}$ ) [21], those of $\gamma$-alumina (at $2 \theta=19^{\circ}, 39^{\circ}, 46^{\circ}$ and $67^{\circ}$ ) [22] and those composing the porcelain disc itself (quartz and mullite) [23].

Next, we examined the roughness of the sol-gel glazed porcelain surfaces and compared it to the non-glazed substrates, using an optical profilometer-see typical 3D image in Fig. 7 and Table 1 for the areal surface roughness (Sa) obtained from the measurements. It is seen that glazing the disc with colorless sol-gel reduces the roughness by $43 \%$, which is manifested in the highly glossy appearance of the coating. Interestingly, the addition of the colorants to the coating renders the surface even smoother-we attribute this added effect to the surfactant nature of the colorants, as evident from their structures (Scheme 1).

Water droplet contact angles were measured in order to estimate the hydrophilic/hydrophobic nature of the sol-gel coating on the porcelain substrate. The average water droplet contact angle for the brilliant blue FCF@SG coating was found to be $66^{\circ}$, similar to that of the uncoated surface $-60^{\circ}$, showing here again that both the coating and the porcelain surface are aluminosilicate materials and thus exhibit similar hydrophilic character. In addition, the kinetics of the water penetration into the sol-gel coating was measured by monitoring the decrease in the water droplet height with time. Figure 8 shows the water 
Fig. 5 FIB tomography of brilliant blue FCF@SG coated on porcelain. (a) SEM image of the analyzed cross-section. Depth profiles of (b) aluminum and (c) carbon. Penetration is from right to left, starting at 300 microns (the interface with air), and ending at 0 . The vertical line indicates the border between the substrate and the coating
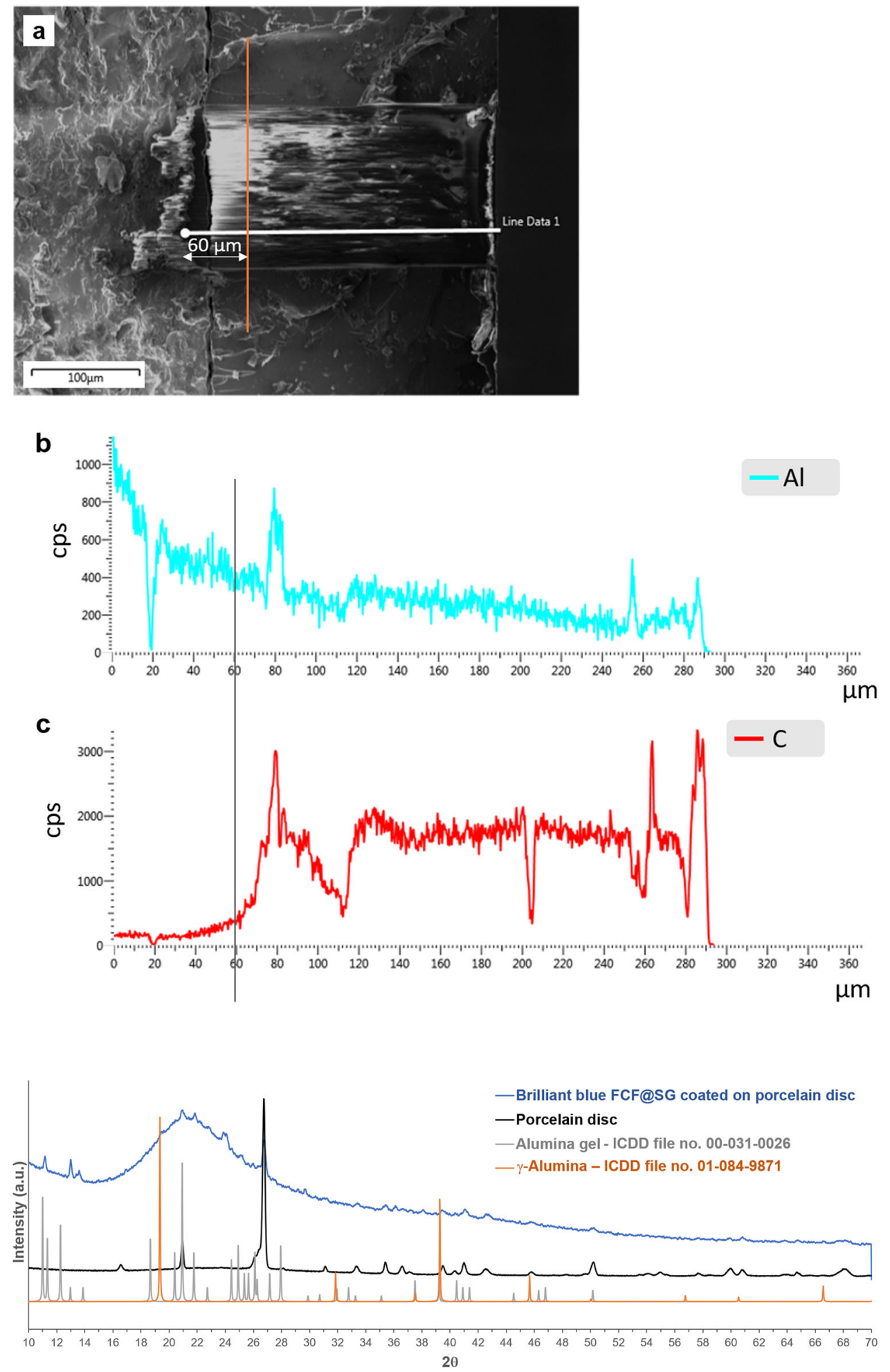

Fig. 6 XRD diffraction pattern of brilliant blue FCF@SG coated on porcelain with some reference patterns $[20,21]$
We now move to the optical features of the dye@SG glazes. For measuring the absorbance spectra of the glazes, we used the transparent glass slides coated samples and compared the resulting spectra to that of the free dye in a solution of DMSO- $\mathrm{H}_{2} \mathrm{O}$ (1:1) (Fig. 9). A colorless sol-gel coated glass slide, which has a low absorbance (up to penetration kinetics of water into brilliant blue FCF@SG glazed porcelain disc, compared to that of the non-coated porcelain surface. It is seen that the water penetration process rate is decreased by half $\left(0.026 \mathrm{~min}^{-1}\right.$ for the uncoated surface and $0.013 \mathrm{~min}^{-1}$ for the coated one), which implies that the sol-gel coating lowers the interfacial porosity. 

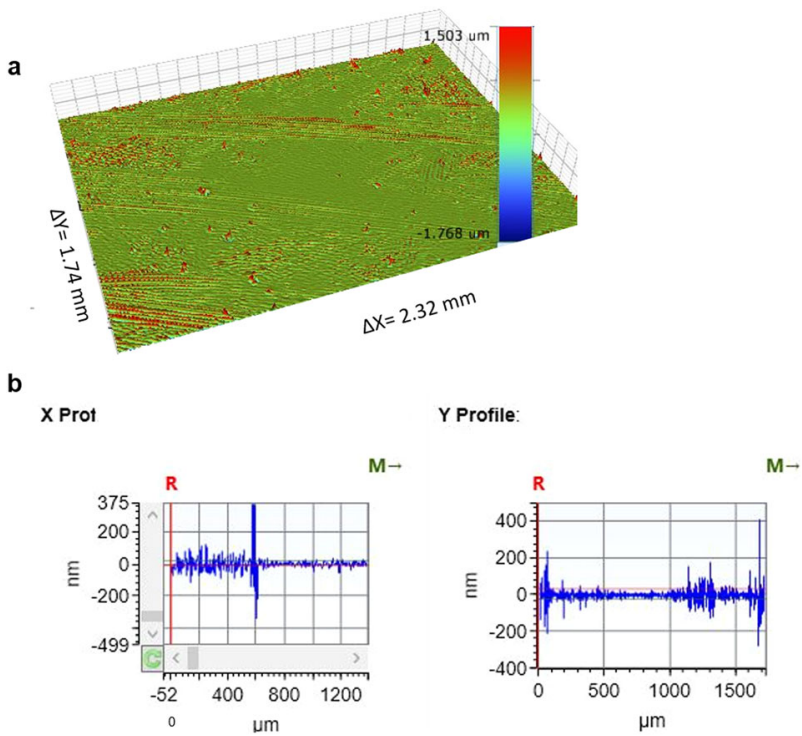

Fig. 7 (a) 3D Optical profilometer image of brilliant blue FCF@SG coated porcelain. (b) optical roughness profile along arbitrary $\mathrm{x}$ and y lines

Table 1 Surface roughness of coated porcelain discs

\begin{tabular}{ll}
\hline Sample name & Surface roughness, Sa (nm) \\
\hline Uncoated porcelain disc & 716 \\
Colorless sol-gel & 407 \\
Curcumin@SG & 131 \\
Allura red+carmine@SG & 107 \\
Brilliant blue FCF@SG & 77 \\
\hline
\end{tabular}

0.06 a.u.), served as the blank for the colored sol-gel glazes. It is seen that the colored sol-gel glazes display the characteristic spectral peaks of the free dye molecule, indicating that the dye molecules remain intact upon entrapment. Some broadening and shifts (see the $\sim 40 \mathrm{~nm}$ blue shift of the curcumin@SG glaze compared to the free dye form) are seen, reflecting the heterogeneity and distribution of chemical environments of the sol-gel cages within which the dye dopant molecules resides, which is different from the homogeneous environment of a DMSO- $\mathrm{H}_{2} \mathrm{O}$ solution. The emission spectra of the fluorescent curcumin@SG glazes coated on a porcelain disc and on a glass slide due to excitation at $421 \mathrm{~nm}$, are plotted in Fig. 10 and compared to that of curcumin in a solution of DMSO- $\mathrm{H}_{2} \mathrm{O}(1: 1)$. It is seen that the curcumin, in both entrapped and dissolved forms, displays a broad emission spectrum, and that the emission maxima positions are shifted from each other, i.e., $510 \mathrm{~nm}$ for the curcumin@SG coated porcelain, $525 \mathrm{~nm}$ for the curcumin@SG coated glass and 569 nm for curcumin in DMSO- $\mathrm{H}_{2} \mathrm{O}$ solution. The molecular environment of curcumin in the hybrid sol-gel cage is less polar than that in DMSO: $\mathrm{H}_{2} \mathrm{O}$ solution, leading to that shift.

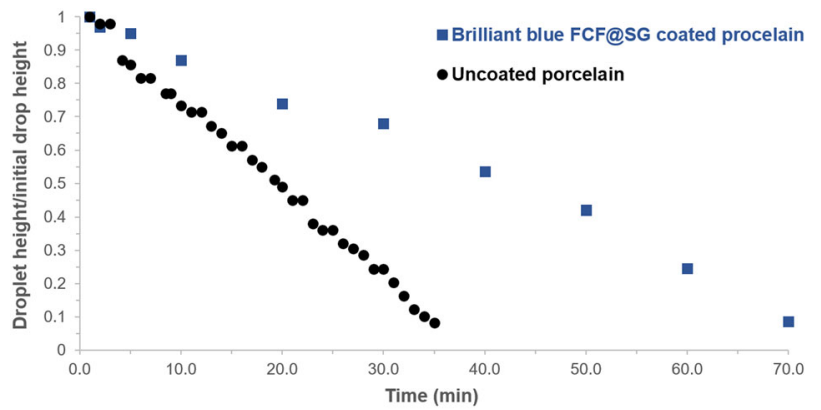

Fig. 8 Water penetration kinetics into brilliant blue FCF@SG coated on porcelain, compared to the uncoated disc



Fig. 9 UV-Vis spectra of the dye@SG coated glass slides and of the dyes in a solution of DMSO: $\mathrm{H}_{2} \mathrm{O} 1: 1$

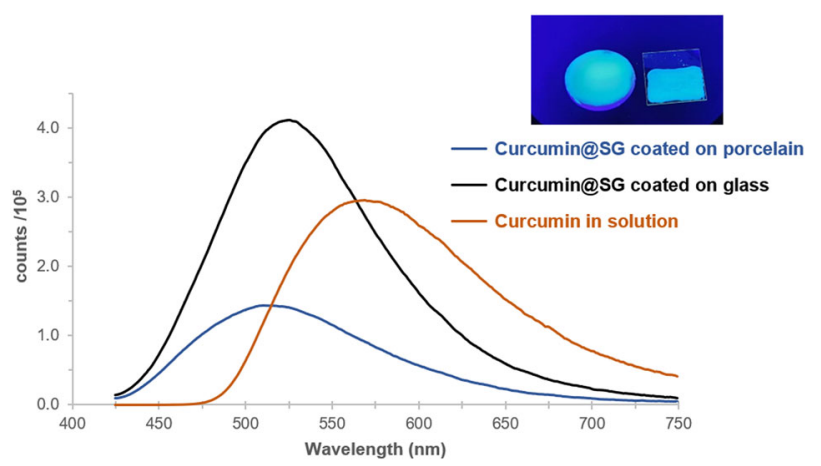

Fig. 10 Fluorescence spectra of curcumin@SG coated on porcelain and on glass, and of curcumin in solution of DMSO: $\mathrm{H}_{2} \mathrm{O}$ 1:1. Inset: coated samples iluminated under $364 \mathrm{~nm}$ UV-lamp

An important advantage of using organic colorants is the ability to remove the color of the coating by heat treatment, a concept which is impossible with inorganic colorants and thus complicates the reuse and the recycling processes. This ability is demonstrated in Fig. 11, which shows that heating a brilliant blue FCF@SG glazed porcelain disc to $950^{\circ} \mathrm{C}$ completely removes the color, thus opening the possibility of recoloring or reusing the porcelain disc in subsequent steps. Finally, qualitative chemical durability tests were performed on the coated surfaces by rinsing them with various solvents (acetone, 
ethanol, isopropanol, and soap water) at room temperature. The coatings showed stability upon exposure to these solvents with no leaching into the solvents or color hue alteration. In addition, a scratch test was performed by a sharp object resulting with no cracking or other stressrelated effects. Preliminary test of light-stability was performed by exposing the glass coated samples to sun-light for seven days: slight decay in the blue was observed, while the other dyes were stable; longer duration tests will be reported separately.

The ability to incorporate organic colorants in ceramic glazes through the sol-gel process is general and not limited to the human-use approved colors used above; of course, other organic colorants can be introduced, such as rhodamine 6G--see a pallet of colors in Fig. 12 and Table 2 - which demonstrate the versatility and the generality of the sol-gel glazing method. In contrast to using inorganic colorant in glazes, which often change their color upon firing due to their reaction with the silica, transforming them from transition metal oxides to transition metal silicates, the sol-gel process provides chemical and physical inertness towards the organic colorants. This makes the sol-gel glazing technique very useful, enabling the artist to paint in a 'WYSIWYG' (What You See Is What You Get) style. Indeed, some preliminary proof-of-concept artistic work is shown in Fig. 13 where we prepared several colors and shades according to the general procedure and applied
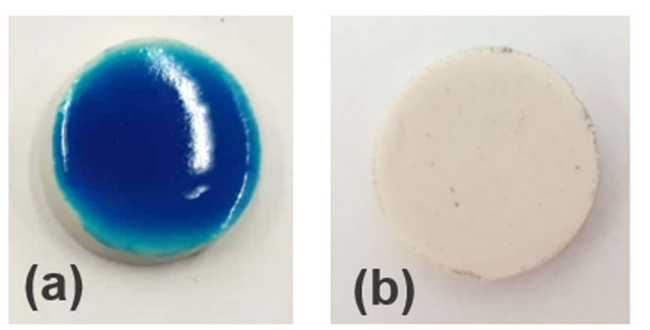

Fig. 11 Recyclability of the color glazing: Brilliant blue FCF@SG coated on a porcelain disc (a) before and (b) after firing at $950^{\circ} \mathrm{C}$ them on some premade porcelain objects (i.e., beads and flat surface) by brushing in a "freestyle" manner-the options are limitless.

\section{Conclusion}

We have shown a way for obtaining colored environmentally safe glazes at temperatures of up to $80^{\circ} \mathrm{C}$ by construction of a sol-gel derived aluminosilicate hybrid matrix with organic dyes. The procedure provides a low energy cost formation of colored glazes for industrial design and artistic purposes on hydroxyl terminated substrates such as glass substrates and porcelain. The glazed layers are 200-300 microns thick, have good adhesion, and have shown stability towards scratching and exposure to solvents. Spectroscopic analysis shows that the original

Table 2 Some additional glazing coloration showing the generality (Fig. 12)

\begin{tabular}{llr}
\hline Glaze label & Colorant name & Concentration in DMSO $(\mathrm{mg} / \mathrm{mL})$ \\
\hline $\mathrm{a}$ & Tartrazine & 2.0 \\
$\mathrm{~b}$ & & 20.0 \\
$\mathrm{c}$ & Fluorescein & 230.0 \\
$\mathrm{~d}$ & Rhodamine 6G & 60.0 \\
$\mathrm{e}$ & & 20.0 \\
$\mathrm{f}$ & & 2.0 \\
$\mathrm{~g}$ & Safranin + & 2.0 \\
& Brilliant blue FCF & 0.4 \\
$\mathrm{~h}$ & Safranin + & 10.0 \\
& Brilliant blue FCF & 2.0 \\
$\mathrm{i}$ & Brilliant blue FCF & 2.0 \\
$\mathrm{j}$ & Tartrazine + & 1.0 \\
& Brilliant blue FCF & 1.0 \\
$\mathrm{k}$ & Tartrazine + & 10.0 \\
& Brilliant blue FCF & 10.0 \\
\hline
\end{tabular}



Fig. 12 A pallet of dye@SG glazes colors, brushed on porcelain disc (upper raw) and on glass slides. From left to right (see also Table 2): (a) Low dye loading tartrazine@SG. (b) High dye loading tartrazine@SG. (c) Fluorescein@SG. (d) Low dye loading rhodamine 6G@SG. (e) Medium dye loading rhodamine 6G@SG. (f) High dye loading rhodamine6G@SG. (g) High mixed dyes loading brilliant blue FCF + safranin@SG. (h) Low mixed dyes loading brilliant blue FCF@safranin@SG. (i) Low dye loading brilliant blue. (j) Low mixed dyes loading brilliant blue FCF + tartarazine@SG. (k) High mixed dyes loading brilliant blue FCF + tartarazine@SG 
a



b

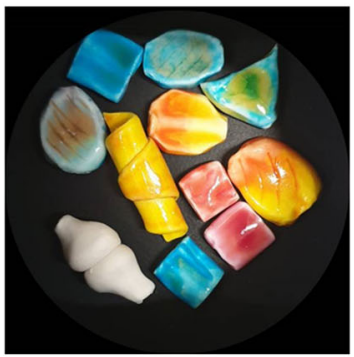

C

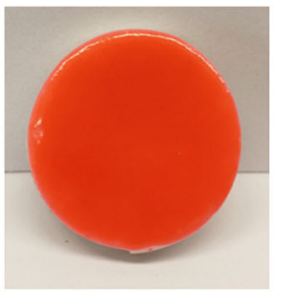

d

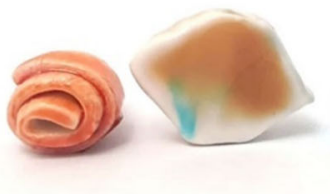

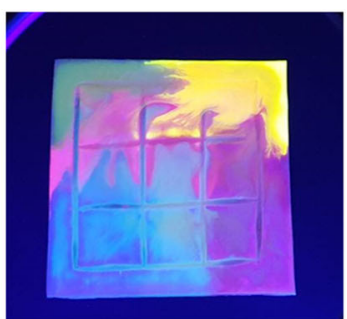
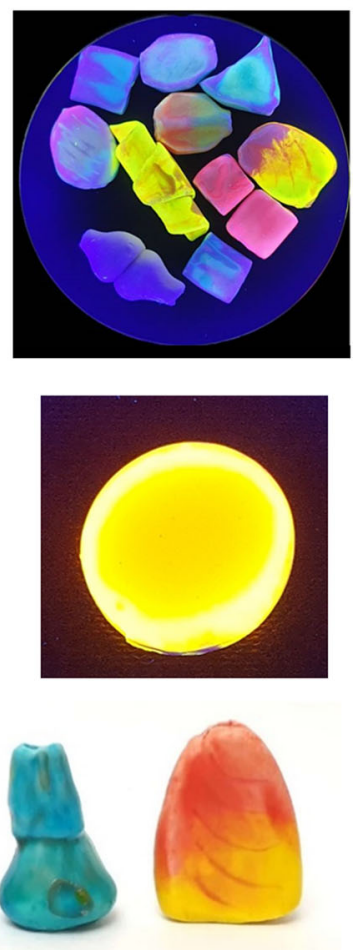

Fig. 13 Dye@SG glazed porcelain artwork. (a) $7 \times 7 \mathrm{~cm}$ tile under normal light (left) and its luminescence under UV light (right). (b) beads - one cm range (normal and UV light). (c) Rhodamine 6G@SG on porcelain disc under normal light (left) and its luminescence under UV light (right). (d) Glazing of various objects (1 cm range)

color-shades remain intact when incorporated in the glaze. Color removal-a classical problem in traditional glass technology-is solved here by firing, resulting in total color removal. This method has a wide potential as a generic solution for safety, health and environmental. Moreover, this method opens new possibilities for the artist and for the designer, by the use of the very large library of organic colorants of the various optical effects that they offer.

\section{Compliance with ethical standards}

Conflict of interest The authors declare no competing interests.

Publisher's note Springer Nature remains neutral with regard to jurisdictional claims in published maps and institutional affiliations.

Open Access This article is licensed under a Creative Commons Attribution 4.0 International License, which permits use, sharing, adaptation, distribution and reproduction in any medium or format, as long as you give appropriate credit to the original author(s) and the source, provide a link to the Creative Commons license, and indicate if changes were made. The images or other third party material in this article are included in the article's Creative Commons license, unless indicated otherwise in a credit line to the material. If material is not included in the article's Creative Commons license and your intended use is not permitted by statutory regulation or exceeds the permitted use, you will need to obtain permission directly from the copyright holder. To view a copy of this license, visit http://creativecommons. org/licenses/by/4.0/.

\section{References}

1. Back M, Gonella F, Hreglich S, Pires de Matos A, Pantano C, Parker J, Tanabe S, Toso C The future of glass colour Round-Table, Glass Art Society Conference 2018, Murano - The Glass Path. https://www.jmbglass.com/inmurano-eu-pdf. Accessed 12 Oct 2021

2. Rossini P, Matteucci G, Guerzoni S (2009) Atmospheric fall-out of metals around the Murano glass-making district (Venice, Italy) Environ Sci Pollut Res 171(17):40-48. https://doi.org/10.1007/ S11356-009-0122-8

3. Udatný M, Mihaljevič M, Šebek O (2014) Release of mobile forms of hazardous elements from glassworks fly ash into soils. Environ Geochem Health 36:855-866. https://doi.org/10.1007/ S10653-014-9604-9

4. Jani Y, Hogland W (2018) Chemical extraction of trace elements from hazardous fine fraction at an old glasswork dump. Chemosphere 195:825-830. https://doi.org/10.1016/j.chemosphere.2017.12.142

5. Nyqvist F, Helmfrid I, Augustsson A, Wingren G (2017) Increased cancer incidence in the local population around metalcontaminated glassworks sites. J Occup Environ Med 59:e84-e90. https://doi.org/10.1097/JOM.0000000000001003

6. Spagnolo S, Gonella F, Viglia S, Ulgiati S (2018) Venice artistic glass: Linking art, chemistry and environment - A comprehensive emergy analysis. J Clean Prod 171:1638-1649. https://doi.org/10. 1016/j.jclepro.2017.10.074

7. Turner A (2019) Heavy metals in the glass and enamels of consumer container bottles. Environ Sci Technol 53:8398-8404. https://doi.org/10.1021/ACS.EST.9B01726

8. Simoneau C, Beldi G, Peltzer M, Jakubowska N (2017) Towards suitable tests for the migration of metals from ceramic and crystal tableware: Work in support of the revision of the Ceramic Directive 84/500/EEC, EUR 28872 EN. Publications Office of the European Union, Luxembourg

9. Avnir D, Kaufman VR, Reisfeld R (1985) Organic fluorescent dyes trapped in silica and silica-titania thin films by the sol-gel method. Photophysical, film and cage properties. J Non Cryst Solids 74:395-406. https://doi.org/10.1016/0022-3093(85)90081-X

10. Zayat M, Almendro D, Vadillo V, Levy D (2017) Sol-Gel Materials for Optics and Electrooptics. In: Handbook of Sol-Gel Science and Technology. Springer International Publishing, pp 1-28

11. Biswas PK (2011) Sol-gel thin films for optics and photonics. J Sol-Gel Sci Technol 59:456-474. https://doi.org/10.1007/S10971010-2368-5

12. Lebeau B, Innocenzi P (2011) Hybrid materials for optics and photonics. Chem Soc Rev 40:886-906. https://doi.org/10.1039/ c0cs00106f

13. Schottner G, Kron J, Deichmann A (1998) Industrial Application of Hybrid Sol-Gel Coatings for the Decoration of Crystal Glassware J Sol-Gel Sci Technol 13:183-187. https://doi.org/10. 1023/a:1008600732596 
14. Sanchez C, Lebeau B, Chaput F, Boilot JP (2003) Optical properties of functional hybrid organic-inorganic nanocomposites. Adv Mater 15:1969-1994. https://doi.org/10.1002/adma.200300389

15. Miorin E, Battagliarin M, Progetti E, Guglielmi M (2003) Stainresistant sol-gel silica coatings on stoneware tile. Am Ceram Soc Bull 82:52-57

16. Akarsu M, Burunkaya E, Tunali A, Tamsü Selli N, Arpaç E (2014) Enhancement of hybrid sol-gel coating and industrial application on polished porcelain stoneware tiles and investigation of the performance. Ceram Int 40:6533-6540. https://doi.org/10. 1016/j.ceramint.2013.11.106

17. Bondioli F, Taurino R, Ferrari AM (2009) Functionalization of ceramic tile surface by sol-gel technique. J Colloid Interface Sci 334:195-201. https://doi.org/10.1016/j.jcis.2009.02.054
18. Kron J, Deichmann K, Schottner G (2003) Process for coating surfaces using hybrid polymer materials. US Patent 7067177 B2, 27 June 2003

19. Casasola R, Ma Rincón J, Romero M (2012) Glass-ceramics glazes for ceramic tiles-a review. J Mater Sci 47:553-582. https:// doi.org/10.1007/s10853-011-5981-y

20. Akkopru B, Durucan C (2007) Preparation and microstructure of sol-gel derived silver-doped silica. J Sol-Gel Sci Technol 432 (43):227-236. https://doi.org/10.1007/S10971-007-1561-7

21. ICDD file no. 00-031-0026

22. ICDD file no. 01-084-9871

23. Aydin T, Kara A (2014) Effect of spodumene addition on pyroplastic deformation of porcelain stoneware. J Ceram Process Res 15:486-491. https://doi.org/10.36410/jcpr.2014.15.6.486 